\title{
Proteína C reactiva y procalcitonina como marcadores de infección bacteriana en niños con neutropenia febril posterior a trasplante alogénico de progenitores hematopoyéticos
}

\author{
Nadia Schmidt ${ }^{1}$, Julia Palma ${ }^{1,2}$, Alejandra King ${ }^{1,2}$, María Elena \\ Santolaya ${ }^{1,3}$. \\ $C$ reactive protein and procalcitonin levels \\ for the diagnosis of invasive bacterial \\ infections in allogenic hematopoietic stem \\ cell transplantation recipients
}

Background: The main causes of complications of allogenic hematopoietic stem cell transplantation are infections and graft versus host disease. Aim: To assess the predictive value of $\mathrm{C}$ reactive protein (CRP) and procalcitonin (PCT) in the diagnosis of invasive bacterial infections in children with febrile neutropenia after an allogenic hematopoietic stem cell transplantation. Material and methods: Prospective follow up of patients aged 18 years or less, with febrile neutropenia after an allogenic hematopoietic stem cell transplantation. In all patients, cultures from sterile sites, CRP and PCT determinations were done. CRP levels were also measured prior to transplantation and three times per week for 30 days after the procedure. An independent evaluator, blinded to the results of CRP and PCT, classified children as with or without invasive bacterial infection. Results: Thirty three patients aged $9 \pm 5$ years (21 males) were studied. Eight had an invasive bacterial infection. Sensitivity, specificity, positive and negative predictive values of a $\mathrm{CRP} \geq 90 \mathrm{mg} / \mathrm{L}$ for the diagnosis of invasive bacterial infection were 25, 80, 29 and 77\%, respectively. The figures for a PCT $\geq 0.7 \mathrm{ng} / \mathrm{ml}$ were 43, 78, 38 and $82 \%$, respectively. No differences in repeated CRP values measured during evolution, were observed. Conclusions: A CRP $\geq 90 \mathrm{mg} / \mathrm{L}$ or a PCT $\geq 0.7 \mathrm{ng} / \mathrm{ml}$ had a high specificity and negative predictive value but low sensitivity for the diagnosis of invasive bacterial infections in recipients of allogenic hematopoietic stem cell transplantation (Rev Méd Chile 2007; 135: 982-89).

(Key w ords: Bacterial infections; C-Reactive protein; Hematopoietic stem cells)

Recibido el 17 de agosto, 2006. Aceptado el 26 de febrero, 2007.

Financiamiento: Proyecto FONDECYT 1040907. Sin intervención en diseño del estudio, recolección de datos, ni análisis de resultados. Si en procesamiento de muestras estudiadas.

${ }^{1}$ Departamento de Pediatría Oriente, Facultad de Medicina, Universidad de Chile. ${ }^{2}$ Unidad de Trasplante de Médula Ósea, Hospital Luis Calvo Mackenna. ${ }^{3}$ Unidad de Infectología, Hospital Luis Calvo Mackenna. Santiago de Chile.

Correspondencia a: Dra. Nadia Schmidt. La Fragua 6194,

Peñalolén. Santiago. E mail: nadiaschmidt@gmail.com 
$\mathrm{E}^{1}$ trasplante de progenitores hematopoyéticos (TPH) es un procedimiento terapéutico validado en pediatría para patologías oncológicas y no oncológicas. La morbimortalidad asociada al TPH ha disminuido en las últimas décadas debido al uso de regímenes de acondicionamiento menos tóxicos, cambio en las pautas de inmunosupresión y mejoría en los tratamientos de soporte, siendo aún las principales causas de morbimortalidad las asociadas a infecciones y a la enfermedad injerto contra huésped aguda (EICH ag) ${ }^{1,2}$.

Se ha descrito que alrededor de $80 \%$ de los pacientes sometidos a algún tipo de TPH presentan al menos un episodio de neutropenia febril (NF); de éstos, 30\% a 50\% presenta fiebre de origen desconocido, $25 \%$ a $50 \%$ bacteriemia $\sin$ foco y $15 \%$ a $20 \%$ infecciones bacterianas localizadas. Las especies que causan infecciones severas en estos pacientes son en $70 \%$ cocáceas Gram positivo y en $30 \%$ bacilos Gram negativo, existiendo mayor incidencia de bacteriemia y mortalidad en el TPH alogénico que en el autólogo, debido a un mayor tiempo de neutropenia, uso de acondicionamiento más mieloablativo y mayores diferencias inmunológicas de histocompatibilidad entre donante y receptor ${ }^{1-3}$.

Considerando el riesgo de las infecciones bacterianas en niños con TPH alogénico, es importante contar con parámetros objetivos que permitan su diagnóstico precoz. Dentro de los marcadores de infección conocidos destacan proteína $\mathrm{C}$ reactiva (PCR) y procalcitonina (PCT). PCR es un reactante de fase aguda que se origina a nivel hepático, cuyo nivel sérico normal en población pediátrica sana y niños con cáncer sin infección es $<10 \mathrm{mg} / \mathrm{L}^{4,5}$. En nuestra experiencia nacional en niños con cáncer y NF, valores séricos $>40 \mathrm{mg} / \mathrm{L}$ se relacionan con presencia de infección bacteriana ${ }^{4}$, y valores $\geq 90 \mathrm{mg} / \mathrm{L}$ se relacionan con infección bacteriana invasora (IBI) ${ }^{6}$. PCT es un polipéptido cuyos niveles son prácticamente indetectables en individuos sanos $(<0,5 \mathrm{ng} / \mathrm{ml})$, aumenta levemente en relación a infecciones virales y bacterianas localizadas $(0,5-2 \mathrm{ng} / \mathrm{ml})$, se eleva en forma moderada en el síndrome de respuesta inflamatoria sistémica de origen no infeccioso (5-20 ng/ml), y presenta un marcado incremento en infecciones bacterianas sistémicas, donde alcanza niveles entre 10 y $1.000 \mathrm{ng} / \mathrm{ml}^{7-9}$. Se ha propuesto que, en pacientes con cáncer y
$\mathrm{NF}$, niveles $>2 \mathrm{ng} / \mathrm{ml}$ serían predictores de bacteriemia, con alta sensibilidad y especificidad ${ }^{10}$. Al ser comparada con PCR, PCT sería más precoz en su ascenso y más dinámica en la normalización de sus valores, siendo útil tanto en el diagnóstico como en el seguimiento de pacientes con enfermedades infecciosas ${ }^{11-15}$.

La hipótesis de este estudio es que PCR y PCT serían pruebas diagnósticas útiles en el diagnóstico de IBI en niños con NF post TPH alogénico. El objetivo es evaluar la sensibilidad (S), especificidad (E), valor predictivo positivo (VPP) y valor predictivo negativo (VPN) de PCR y PCT en el diagnóstico de IBI en niños con NF posterior al TPH alogénico, y describir la evolución de los valores de PCR sérica durante los primeros 30 días post TPH.

\section{Pacientes y MÉtodo}

Diseño del estudio y población estudiada. Se realizó un estudio prospectivo en pacientes $\leq 18$ años con patología oncológica y no oncológica, sometidos a TPH alogénico entre enero 2003 y diciembre 2005 en la Unidad de Trasplante de Médula Ósea del Hospital Luis Calvo Mackenna (HLCM). En Chile, esta unidad es de referencia nacional para los pacientes del Programa Infantil Nacional de Drogas Antineoplásicas (PINDA) ${ }^{2}$. Los pacientes fueron invitados a participar a su ingreso a la Unidad de Trasplante de Médula Ósea, previo al acondicionamiento, y fueron ingresados al estudio el día previo al TPH, luego de que sus padres o tutores legales firmaron un consentimiento informado. La investigación respetó las normas éticas internacionales. El estudio y el consentimiento informado fueron evaluados y aprobados por el comité de ética científico pediátrico del Servicio de Salud Metropolitano Oriente.

Evaluación y seguimiento. Luego de ser enrolados en el estudio, los niños fueron evaluados por uno de los investigadores (NS) y fueron caracterizados según edad, género, diagnóstico y acondicionamiento utilizado. Se tomaron muestras de PCR y PCT en forma basal (día previo al TPH) y el día del TPH (día 0). Se realizó monitoreo posterior al TPH con medición de temperatura cada $4 \mathrm{~h}$ y recuento absoluto de neutrófilos (RAN) en forma 
diaria. Se consideró que el paciente presentaba una NF si tenía un RAN $\leq 500 / \mathrm{mm}^{3}$ y al menos una medición de temperatura axilar $\geq 38,3^{\circ} \mathrm{C}$. Todo paciente enrolado que presentó NF se mantuvo en el estudio, los pacientes que no presentaron NF fueron retirados del estudio.

En todo paciente que presentó NF se aplicó el protocolo de diagnóstico de IBI, usando como estándar diagnóstico ideal la toma de cultivos de sitio estéril: sangre, catéter venoso central (CVC) (1 muestra de cada rama de CVC y 1 muestra de vía periférica) y orina; y como prueba diagnóstica, la determinación de PCR y PCT el día de inicio de la NF y a las 24 h de evolución. Se solicitó además hemograma, orina completa, y los siguientes exámenes según orientación clínica: radiografía, ecografía, tomografía y resonancia magnética. Posteriormente se midió temperatura en forma horaria y se instauró tratamiento antimicrobiano con vancomicina $40 \mathrm{mg} / \mathrm{kg} /$ día y ceftazidima 100 $\mathrm{mg} / \mathrm{kg} /$ día por vía intravenosa (IV). Si el paciente evolucionó afebril, sin foco clínico y con cultivos negativos, se mantuvo con antimicrobianos hasta completar $72 \mathrm{~h}$ afebril y tener RAN $>500 / \mathrm{mm}^{3}$. Si evolucionó en buenas condiciones, sin signos clínicos de infección, pero con algún cultivo de sitio estéril positivo, se mantuvo o ajustó el tratamiento antimicrobiano según el microorganismo aislado hasta la negativización de los cultivos. Si evolucionó febril o con deterioro clínico, se tomaron nuevamente hemocultivos y urocultivo y se agregó amikacina $15 \mathrm{mg} / \mathrm{kg} /$ día IV. Si el paciente se mantuvo febril a los 5-7 días de iniciado el tratamiento, se agregó anfotericina $\mathrm{B}$ deoxicolato 1 $\mathrm{mg} / \mathrm{kg} /$ día IV, previo estudio con hemograma, orina completa, hemocultivos, urocultivo, radiografía de tórax y según clínica: ecografía, tomografía y resonancia magnética. El tratamiento antimicrobiano se mantuvo hasta controlado el cuadro clínico con negativización de cultivos, si éstos fuemon positivos, y recuperación de la neutropenia severa (RAN $>500 / \mathrm{mm}^{3}$ ). En casos de infección fúngica, el tratamiento se mantuvo por 21 días.

Con el objeto de evaluar la evolución de PCR durante los primeros 30 días post TPH, se determinó su nivel sérico desde el día previo a la infusión de precursores hematopoyéticos (basal) hasta el día 5 post-TPH (día +5$)$ y luego 3 veces por semana. Cuando el paciente presentó NF y completó $72 \mathrm{~h}$ afebril, se continuó 3 veces por semana hasta el día 30 post-TPH (día +30) o antes si era dado de alta o fallecía.

Al finalizar cada episodio de NF, los pacientes fueron clasificados por un investigador ciego (JP), de acuerdo al estándar diagnóstico ideal, en dos grupos, según si presentaban o no la condición en estudio: niños con IBI demostrada, y niños sin IBI demostrada.

Medición de PCR y PCT. Se obtuvo 3 cc de sangre en un tubo de ensayo sin heparina. Para medir PCR, 1 cc de la muestra se incubó con antisuero (Orion Diagnostica ${ }^{\circledR}$ ) obteniéndose un complejo PCR-antisuero que fue cuantificado mediante ensayo inmunohistoquímico con un autoanalizador Vitalab Selectra (Tecnigen $\left.{ }^{\circledR}\right)^{5,6}$. Para medir PCT, 2 cc de la muestra se procesaron por método de inmunoluminometría (Lumitest Brahms ${ }^{\circledR}$ ) que mide el complejo formado por dos anticuerpos (antikatacalcina y anticalcitonina) contra las respectivas porciones de la molécula de $\mathrm{PCT}^{7,8}$. Las determinaciones fueron realizadas en diferido, por un evaluador ciego a los datos clínicos y a los resultados de los cultivos de sitio estéril realizados a los pacientes (AK).

Análisis estadístico. Se calculó S, E, VPP y VPN de PCR y PCT para el diagnóstico de IBI el día de inicio de la NF y a las $24 \mathrm{~h}$, comparándolo con el estándar diagnóstico ideal: cultivos positivos de sitio estéril. Los valores de corte para cada variable fueron extrapolados de aquellos definidos a través de curvas ROC (Receiver Operator Characteristic) en niños chilenos con cáncer y NF posquimioterapia $5,16,17$.

Se describió la evolución de los valores de PCR en los dos grupos, desde el valor basal hasta el día +30 , o antes si el paciente era dado de alta 0 fallecía. Se compararon en ambos grupos los valores basales, del día del TPH, del día de inicio de la NF, día +1 de la NF y los valores máximos, a través de $\mathrm{T}$ de Student. Las variables discontinuas fueron evaluadas a través de Chi cuadrado. Fue considerado significativo un valor de $P<0,05$. El análisis estadístico fue hecho usando STATA 7.0 (StataCorp LP, 2000; Texas, USA). 


\section{RESUlTADOS}

Descripción de la población enrolada. Durante el período de estudio, comprendido entre el 1 de enero de 2003 y el 31 de diciembre de 2005, se realizaron 56 TPH en 56 niños en la Unidad de Trasplante de Médula Ósea del Hospital Luis Calvo Mackenna, de los cuales 41/56 (73\%) fueron de tipo alogénico, y fueron invitados a participar, excepto un paciente mayor de 18 años, que no cumplía criterios de inclusión. Luego de que los padres 0 representantes legales aprobaran el respectivo informe de consentimiento, 40 pacientes fueron enrolados. De éstos, 33 fueron evaluables al final del estudio. Tres pacientes fueron retirados porque no desarrollaron NF y 4 porque las tomas de muestra de sangre para determinación de PCR y PCT fueron incompletas. De los 33 pacientes evaluados $8(24 \%)$ pertenecieron al grupo con IBI y 25 (76\%) al grupo sin IBI. Veintiuno (64\%) eran hombres.

La edad promedio fue de 9 años \pm DE 4,6 (rango 0,3-18 años); 6,2 años \pm DE 4,1 (rango 0,33-14 años) para el grupo de niños con IBI y 9,8 años \pm DE 4,5 (rango 1-18 años) para el grupo sin IBI, sin diferencias significativas entre ellos ( $P$ $=0,23$ ). La edad, género, diagnóstico, tipo de donante y acondicionamiento de los pacientes, se detallan en la Tabla 1. El día promedio de presentación de la NF fue 5,6 días \pm DE 2,4 (rango 0-10 días); 4,3 días $\pm \mathrm{DE} 2,5$ (rango 0-7 días) para el grupo con IBI y 5,8 días \pm DE 2,0 (rango 2-10 días) para el grupo sin IBI $(\mathrm{P}=0,14)$.

Los microrganismos aislados en los 8 niños con IBI fueron: Escherichia coli $(\mathrm{n}=2)$, Streptococus grupo viridans $(\mathrm{n}=2)$, Staphylococcus aureus ( $\mathrm{n}=1)$, Klebsiella pneumoniae $(\mathrm{n}=1)$, Neisseria lactamica ( $\mathrm{n}=1)$ y Proteus mirabilis $(\mathrm{n}=1)$, todos procedentes de hemocultivos, excepto un aislamiento de Escherichia coli y Proteus mirabilis en orina.

En los 25 niños sin IBI demostrada, hubo 18 con diagnóstico final de fiebre de origen desconocido, en que el análisis clínico y de laboratorio fue concordante con ausencia de infección bacteriana, y hubo 7 pacientes que tuvieron elementos clínicos o de laboratorio sugerentes de infección bacteriana, pero no cumplieron con el estándar diagnóstico de IBI. Estos 7 niños presentaron los siguientes focos infecciosos: pulmonar, con radio- grafía de tórax compatible ( $\mathrm{n}=2$ ); pulmonar y sinusal, identificados con radiografía de tórax y tomografía de cavidades paranasales, respectivamente $(\mathrm{n}=1)$; digestivo, con ecografía abdominal con signos de ileítis $(\mathrm{n}=1)$; cutáneo, con ecografía de partes blandas que mostró colección paramuscular en extremidad inferior $(\mathrm{n}=1)$; cutáneo catalogado clínicamente como foliculitis $(\mathrm{n}=1) \mathrm{y}$ foco oral clínico de mucositis $(n=1)$.

En el período observado fallecieron 2 pacientes: №5 y №27. El primero, presentó una bronconeumonía de diagnóstico clínico y radiológico, evolucionó con requerimiento de drogas vasoactivas y ventilación mecánica. No se aisló microorganismo. El segundo, evolucionó con shock séptico, requirió drogas vasoactivas, ventilación mecánica convencional y de alta frecuencia. Se aisló Streptococcus grupo viridans en sangre.

\section{Evaluación de pruebas diagnósticas}

Evaluación de PCR De los 33 pacientes estudiados, 8 tuvieron la condición de estudio (IBI) y 25 no la tuvieron. Los niveles séricos de PCR el día de diagnóstico de NF y a las $24 \mathrm{~h}$, fueron semejantes en los niños con y $\sin$ IBI $(\mathrm{P}=0,77$ y $\mathrm{P}=0,19$ respectivamente).

De los 8 niños con IBI, 2 tuvieron $\mathrm{PCR} \geq 90$ $\mathrm{mg} / \mathrm{L}$ al ingreso y $20 / 25$ de los sin IBI tuvieron PCR $<90 \mathrm{mg} / \mathrm{L}$. Lo anterior otorga a la prueba una S de $25 \%$, E de $80 \%$, VPP de $29 \%$ y VPN de $77 \%$ (Tabla 2). Luego de 24 h de observación, el valor de PCR sérica $\geq 90 \mathrm{mg} / \mathrm{L}$ mostró una $\mathrm{S}, \mathrm{E}$, VPP y VPN de $50 \%$, 68\%, 33\% y $81 \%$, respectivamente.

Evaluación de PCT. Se evaluaron los valores de PCT en 30/33 pacientes. En tres niños ( $\mathrm{N}^{\circ} 3,4$ y 5) las muestras fueron obtenidas correctamente pero no fueron mantenidas a temperatura adecuada, por lo que fueron desechadas. De los 30 pacientes evaluables, 7 tuvieron IBI y 23 no. El valor sérico de PCT el día del diagnóstico de NF fue semejante en los niños con y sin IBI $(P=0,16)$. Hubo diferencia estadísticamente significativa entre los niños con y sin IBI en la determinación realizada a las $24 \mathrm{~h}$ de iniciada la NF $(\mathrm{P}=0,03)$ y en el valor máximo durante la $\mathrm{NF}(\mathrm{P}=0,005)$.

Usando el valor de corte de $0,7 \mathrm{ng} / \mathrm{ml}$, PCT el día de diagnóstico de NF fue mayor al valor de corte en $3 / 7$ niños y fue $\leq 0,7 \mathrm{ng} / \mathrm{ml}$ en $18 / 23 \mathrm{sin}$ IBI. La S, E, VPP y VPN el día de diagnóstico de NF 


\section{Tabla 1. C aracterísticas de 33 niños con episodios de neutropenia febril posterior a trasplante alogénico de progenitores hematopoyéticos}

\begin{tabular}{|c|c|c|c|c|c|c|}
\hline № & $\begin{array}{c}\text { Edad } \\
\text { (años) }\end{array}$ & Género & Diagnóstico & $\begin{array}{c}\text { Tipo } \\
\text { donante }\end{array}$ & Acondicionamiento* & $\begin{array}{c}\text { Pacientes } \\
\text { con IBI }\end{array}$ \\
\hline 1 & 14 & M & LA RC 1 & DFI & VP 16(1), CF(2), ICT(3) & \\
\hline 2 & 4 & $\mathrm{~F}$ & LA RC 1 & SCU/DNE & ICT(3), VP 16(1), CF(2), ATG(4) & \\
\hline 3 & 8 & $\mathrm{~F}$ & LA RC 1 & SCU/DNE & ICT(3), VP 16(1), CF(2), ATG(4) & + \\
\hline 4 & 18 & F & LA RC 2 & DFI & VP 16(1), CF(2), ICT(3) & \\
\hline 5 & 11 & M & Aplasia medular & DFI & CF(4), INT(1) & \\
\hline 6 & 9 & $\mathrm{~F}$ & Neutropenia de Kostman & DFI & $\mathrm{B}(3), \mathrm{CF}(2)$ & \\
\hline 7 & 10 & $\mathrm{M}$ & ШA RC 1 & DFI & VP 16(1), CF(2), ICT(3) & \\
\hline 8 & 7 & $\mathrm{~F}$ & LA RC 1 & DFNI & VP 16(1), CF(2), ICT(3) & + \\
\hline 9 & 8 & M & LA RC 1 & DFI & VP 16(1), CF(2), ICT(3) & \\
\hline 10 & 17 & M & LMC & DFI & VP 16(1), CF(2), ICT(3) & \\
\hline 11 & 2 & M & Sd Blackfan Diamond & SCU/DNE & $\mathrm{B}(4), \mathrm{CF}(4), \operatorname{ATG}(4)$ & + \\
\hline 12 & 8 & $\mathrm{~F}$ & ШA RC 2 & DFI & VP 16(1), CF(2), ICT(3) & + \\
\hline 13 & 11 & $\mathrm{M}$ & LA RC 1 & DFNI & VP 16(1), CF(2), ICT(3) & \\
\hline 14 & 9 & $\mathrm{M}$ & LA RC 2 & DFI & VP 16(1), CF(2), ICT(3) & \\
\hline 15 & 8 & $\mathrm{M}$ & LA RC 1 & DFI & VP 16(1), CF(2), ICT(3) & \\
\hline 16 & 5 & $\mathrm{~F}$ & LA RC 1 & DFI & VP 16(1), CF(2), ICT(3) & \\
\hline 17 & 10 & M & LA RC 1 & DFNI & $\mathrm{B}(4), \mathrm{CF}(2), \mathrm{VP} 16(1)$ & \\
\hline 18 & 14 & $\mathrm{~F}$ & ШA RC 2 & DFI & VP 16(1), CF(2), ICT(3) & + \\
\hline 19 & 10 & $\mathrm{M}$ & LA RC 1 & DFI & VP 16(1), CF(2), ICT(3) & \\
\hline 20 & 13 & $\mathrm{M}$ & LA RC 2 & DFI & VP 16(1), CF(2), ICT(3) & \\
\hline 21 & 5 & M & Aplasia medular & DFI & $\mathrm{CF}(4), \mathrm{INT}(1)$ & \\
\hline 22 & 8 & M & Adrenoleucodistrofia ligada a X & SCU/DNE & $\mathrm{B}(4), \mathrm{CF}(2), \operatorname{ATG}(4)$ & \\
\hline 23 & 6 & $\mathrm{~F}$ & LA RC 2 & SCU/DNE & ICT (3), CF(2), ATG(4) & + \\
\hline 24 & 17 & $\mathrm{M}$ & ШA RC 2 & DFI & VP 16(1), CF(2), ICT(3) & \\
\hline 25 & 13 & M & Aplasia medular & DFI & $\operatorname{INT}(1), C F(2)$ & \\
\hline 26 & 15 & M & LA RC 1 & DFI & VP 16(1), CF(2), ICT(3) & \\
\hline 27 & 5 & $\mathrm{M}$ & LA RC 1 & SCU/DNE & ICT(3), CF(2), ATG(4) & + \\
\hline 28 & 0,33 & $\mathrm{M}$ & ICS & SCU/DNE & $\mathrm{B}(4), \mathrm{CF}(4), \mathrm{ATG}(4)$ & + \\
\hline 29 & 5 & F & LA RC 1 & DFI & VP 16(1), CF(2), ICT(3) & \\
\hline 30 & 15 & M & LA RC 2 & DFI & VP 16(1), CF(2), ICT(3) & \\
\hline 31 & 8 & $\mathrm{M}$ & ШA RC 1 & DFI & VP 16(1), ICT(3), CF(2) & \\
\hline 32 & 8 & F & Síndrome mirlodisplásico & DFI & $\mathrm{B}(4), \mathrm{CF}(2)$ & \\
\hline 33 & 1 & F & LMA & DFI & $\mathrm{B}(4), \mathrm{CF}(2)$ & \\
\hline
\end{tabular}

IBI: Infección bacteriana invasora; M: masculino, F: femenino, LA RC 1: leucemia linfoblástica aguda en primera remisión completa; LA RC 2: leucemia linfoblástica aguda en segunda remisión completa; LMC: leucemia mieloide crónica; LMA: leucemia mieloide aguda; ICS: inmunodeficiencia combinada severa; DFI: donante familiar idéntico; DFNI: donante familiar no idéntico; SCU/DNE: Sangre de cordón umbilical de donante no emparentado; VP 16: Etopósido; CF: Ciclofosfamida; B: Busulfan; ICT: Imadiación Corporal Total; INT: Imadiación Nodal Total; ATG: Antiglobulina. *En paréntesis se presenta el número de días de tratamiento.

fue de $43 \%$, 78\%, 38\% y $82 \%$ (Tabla 3 ), siendo de $57 \%, 57 \%, 29 \%$ y $81 \%$ a las 24 h de observación.

Evolución de valores de PCR sérica durante los primeros 30 días post TPH. La evolución de valores de PCR en niños sometidos a TPH alogénico se muestra en la Figura 1. Los valores basales $(\mathrm{P}=0,14)$, del día del TPH $(\mathrm{P}=0,08)$, del día de inicio de la NF, de las $24 \mathrm{~h}$ luego de iniciada la NF y los valores máximos ( $\mathrm{P}=0,86$ ), no mostraron 
Tabla 2. Valores séricos de proténa $C$ reactiva como diagnóstico de infección bacteriana invasora en niños con neutropenia febril posterior a trasplante alogénico de progenitores hematopoyéticos.

\begin{tabular}{|lcrc|}
\hline & $\begin{array}{c}\text { Pacientes con o sin infección bacteriana } \\
\text { Cultivo }(+)\end{array}$ & Cultivo $(-)$ & Total \\
\hline PCR $\geq 90 \mathrm{mg} / \mathrm{L}$ & 2 & 5 & 7 \\
PCR $<90 \mathrm{mg} / \mathrm{L}$ & 6 & 20 & 26 \\
Total & 8 & 25 & 33 \\
\hline
\end{tabular}

Tabla 3. Valores séricos de procalcitonina como diagnóstico de infección bacteriana invasora en niños con neutropenia febril posterior a trasplante alogénico de progenitores hematopoyéticos

\begin{tabular}{|lcrc|}
\hline & $\begin{array}{c}\text { Pacientes con o sin infección bacteriana invasora, según estándar diagnóstico ideal } \\
\text { Cultivo }(+)\end{array}$ & Cultivo $(-)$ & Total \\
\hline PCT $>0,7 \mathrm{ng} / \mathrm{ml}$ & 3 & 5 & 8 \\
PCT $\leq 0,7 \mathrm{ng} / \mathrm{ml}$ & 4 & 18 & 22 \\
Total & 7 & 23 & 30 \\
\hline
\end{tabular}

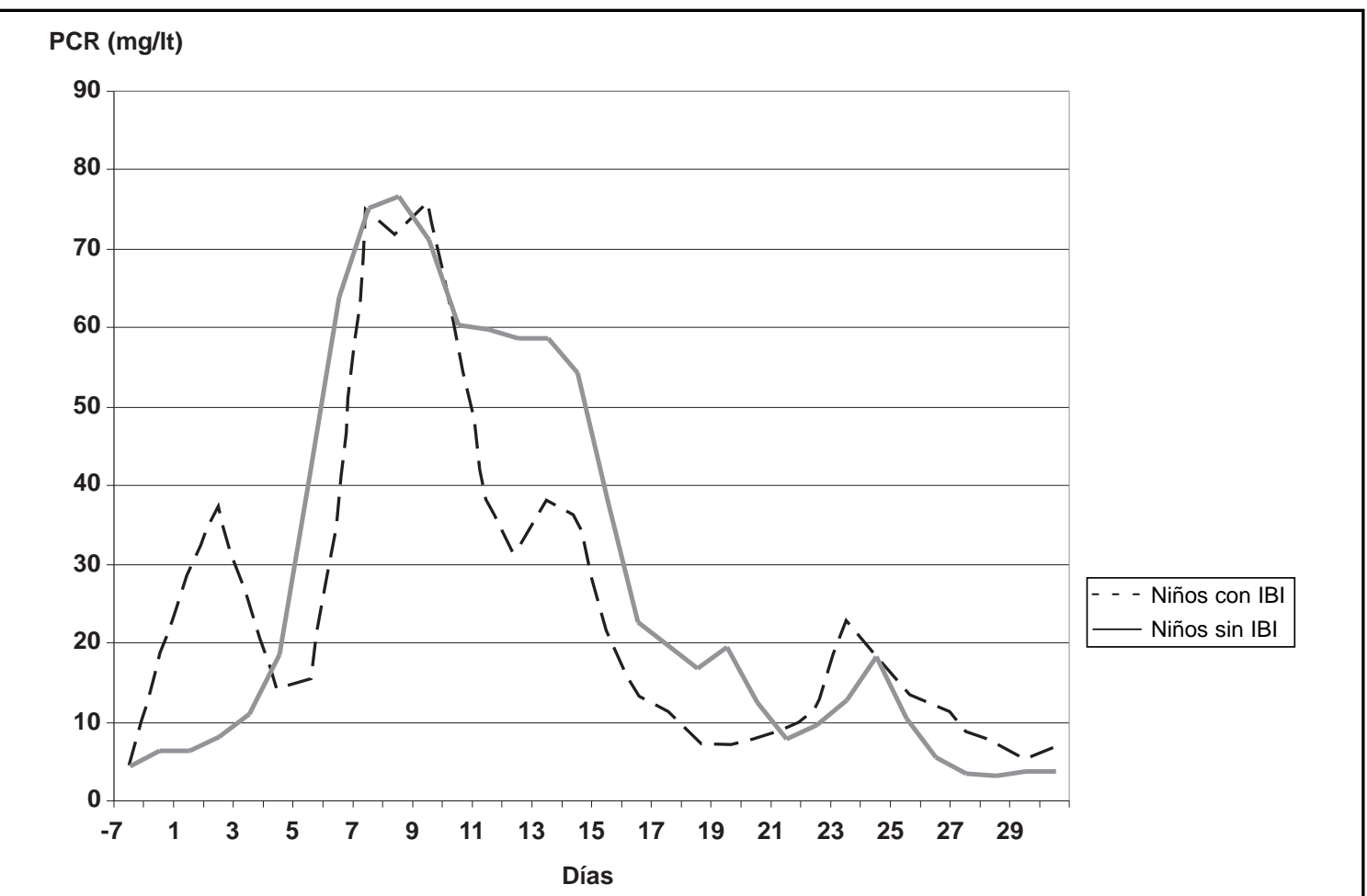

Figura 1. Evolución de valores de proteína C reactiva hasta el día 30 postrasplante alogénico de precursores hematopoyéticos en niños con neutropenia febril, con y sin infección bacteriana demostrada. 
diferencias significativas entre los pacientes con y $\sin$ IBI.

\section{DisCUSIÓN}

Los niños con TPH y NF presentan alto riesgo de IBI, sepsis, shock séptico y falla multiorgánica, por lo que resulta fundamental contar con marcadores biológicos que ayuden al clínico a realizar un diagnóstico precoz. Algunos estudios recientes han explorado la utilidad de PCR y PCT en el diagnóstico de IBI en pacientes con NF sometidos a TPH. Sauer y cols, estudiaron PCR, PCT y endotoxina como indicadores de riesgo de sepsis en 47 niños con TPH, demostrando que valores séricos de $\mathrm{PCR}>50 \mathrm{mg} / \mathrm{L}$ tuvieron $\mathrm{S}$ y E de $100 \%$ y $41 \%$, y valores séricos de PCT $>1 \mathrm{ng} / \mathrm{ml}$ mostraron S y E de $56 \%$ y $87 \%{ }^{11}$. Otra investigación en niños y adultos con TPH alogénico evidenció que valores de PCR $>100 \mathrm{mg} / \mathrm{L}$ mostraron S, E, VPP y VPN de $83 \%$, 61\%, 58\% y 85\% para el diagnóstico de infecciones bacterianas y fúngicas y valores de PCT $>1 \mathrm{ng} / \mathrm{ml}$ tuvieron $\mathrm{S}$ de $70 \%$, E de $61 \%$, VPP de $54 \%$ y VPN de $76 \% 18$.

Respecto a la evolución de PCR entre el TPH y el día +30, y su valor diagnóstico de IBI en NF, vimos que la evolución de los valores de PCR fue similar en los niños con y sin IBI durante el período observado, incluyendo el episodio de NF y la presencia o no de IBI. Esto podría sugerir que los niños con TPH alogénico generan una respuesta inflamatoria no relacionada necesariamente a una infección bacteriana. En este sentido Schots y cols, describieron un aumento de PCR desde el día 5 post-TPH alogénico en adultos que evolucionaron

\section{REFERENCIAS}

1. Mulen C, Nair J, Sandesh S, Chan K. Fever and neutropenia in pediatric hematopoietic stem cell transplant patients. Bone Marrow Trasplantation 2000; 25: 59-65.

2. Palma J, Mosso C, Paris C, Campbell M, Tong X, KIng A. Establishment of a pediatric HSCT program in a public hospital in Chile. Pediatr Blood Cancer 2006; 46: 803-10.

3. Romano V, Castagnola E, Dalorso S, Lanino E, Calvi A, Silvestro S et al. Bloodstream infections can con complicaciones tales como infecciones bacterianas, EICH ag, síndrome de daño capilar, falla renal o neumonitis ${ }^{19}$, y otros estudios evidenciaron aumento de PCR en >15 años con TPH alogénico y EICH ag grado II, III y IV 20,21 .

Con respecto a los niveles de PCT signicativamente diferentes entre los niños con y sin IBI a las $24 \mathrm{~h}$ de diagnóstico de la NF, lo mismo que los valores máximos durante el episodio, esto podría orientar a que valores más elevados de PCT se relacionarían a infecciones bacterianas sistémicas. Asimismo, algunos estudios han relacionado niveles elevados de PCT con IBI, shock séptico y muerte11,13,21, aunque el valor de corte para el diagnóstico de IBI en niños con NF posterior a TPH no se encuentra claramente establecido ${ }^{11,17}$. En relación al momento en que PCT aumenta, Hambach y cols. demostraron que en pacientes con TPH alogénico y sepsis se inicia un alza de PCT a las 24 $\mathrm{h}$ de manifestada la $\mathrm{NF}^{18}$, lo que es concordante con nuestra experiencia. Sin embargo, no conocemos estudios que hayan medido PCT en intervalos menores de tiempo desde el inicio de la NF, por lo cual pudiese existir un incremento más precoz.

En nuestra experiencia reportada en niños con TPH alogénico y NF, PCR no es un parámetro que permita discriminar si existe o no IBI; sin embargo, PCT a las $24 \mathrm{~h}$ de iniciada la NF podría constituir un elemento objetivo de ayuda en la práctica clínica para el diagnóstico de IBI. Desde otro punto de vista, tanto $\mathrm{PCR} \geq 90 \mathrm{mg} / \mathrm{L}$ como $\mathrm{PCT}>0,7 \mathrm{ng} / \mathrm{ml}$ mostraron alta E y VPN, por lo que encontrar valores séricos menores a estos puntos de corte en niños con NF posterior a TPH alogénico, sería un elemento más para los clínicos que ayudaría a hacer menos probable la presencia de IBI.

develop late (after day 100) and/or in the absence of neutropenia in children receiving allogenic bone marrow transplantation. Bone Marrow Trasplantation 1999; 23: 271-5.

4. JaYe D, Ken B. Clinical applications of C-reactive protein in pediatrics. Pediatr Infect Dis J 1997; 16: 735-47.

5. Santolaya M, Cofré J, Beresi V. C-reactive protein: A valuable aid for the management of febrile children with cancer and neutropenia. Clinical Infectious Dis 1994; 18: 589-95.

6. Santolaya M, Alvarez A, Becker A, Cofré J, Enríquez 
N, O’Ryan M et al. Prospective, multicenter evaluation of risk factors associated with invasive bacterial infection in children with cancer, neutropenia and fever. Journal of Clinical Oncology 2001; 14: 3415-21.

7. Casado J, Blanco A. Procalcitonina: un nuevo marcador de infección bacteriana. Anales españoles de pediatría 2001; 54: 69-73.

8. Gendrel D, Bohuon C. Procalcitonin as a marker of bacterial infections. Pediatr Infect Dis J 2000; 19: 679-88.

9. Chiesa C, Panero A, Rossi N, Stegagno M, De Giusti M, OSBORN J ET AL. Reability of procalcitonin concentrations for the diagnosis of sepsis in critically ill neonates. Clinical Infections Diseases 1998; 26: 664-72.

10. Fleischiack G, Kambeck I, Cipic D, Hasan C, Bode U. Procalcitonin in paediatric cancer patients: its diagnostic relevance is superior to that of $\mathrm{C}$ reactive protein, interleukin 6 , interleukin 8 , soluble interleukin 2 receptor and soluble tumour necrosis factor receptor II. British Journal of Haematology 2000; 111: 1093-102.

11. Sauer M, Tiede K, Fuchs D, Gruhn B, Berger D, ZiNTL F. Procalcitonin, C-Reactive Protein, and endotoxin after bone marrow transplantation: identification of children at high risk of morbidity and mortality from sepsis. Bone Marrow Transplantation 2003; 31: 1137-42.

12. Gendrel D, Raymond J, Coste J, Mouln F, Lorrot M, GuERIN S ET AL. Comparison of procalcitonin with C-reactive protein, interleukin 6 and interferonalpha for differentiation of bacterial vs viral infections. Pediatr Infect Dis J 1999; 18: 875-81.

13. Ciaeys R, Vinken S, Spapen H, Eist K, Decochez K, HuYghens L et al. Plasma procalcitonin and C-reactive protein in acute septic shock: clinical and biological correlates. Crit Care Med 2002; 30: 757-62.

14. Franz A, Kron M, Pohlandt F, Steinbach G. Comparison of procalcitonin with interleukin 8,
C-reactive protein and differential white blood cell count for the early diagnosis of bacterial infections in newborn infants. Pediatr Infect Dis J 1999; 18: 666-71.

15. Casado J, Blanco A, Asensio J, Arranz E, Garrote J, NIETO M. Serum procalcitonin in children with suspected sepsis: A comparison with C-Reactive protein and neutrophil count. Pediatr Crit Care Med 2003; 4: 190-5.

16. Santolaya ME, Alvarez AM, Aviles CL, Becker A, O’Ryan M, Paya E et al. Prospective Evaluation of a Model of Prediction of Invasive Bacterial Infection Risk among Children with Cancer, Fever and Neutropenia. Clin Infect Dis 2002; 35: 678-83.

17. Santolaya M, Alvarez AM, Aviles CL, Becker A, O’Ryan M, Paya E et al. Admission clinical and laboratory factors associated with death in children with cancer during a febrile neutropenic episode. Ped Infect Dis J 2007. En prensa.

18. Hambach L, Eder M, Dammann E, Schrauder A, Sy kora K, Dieterich C ET al. Diagnostic value of procalcitonin serum levels in comparison with Creactive protein in allogenic stem cell transplantation. Haematologica 2002; 87: 643-51.

19. Schots R, Van Riet I, Ben Othman T, Trulemans F, De WAEIE M, VAN CAMP B ET AL. Early increase in serum levels of $\mathrm{C}$-reactive protein is an independent risk factor for the occurrence of major complications and 100-day transplant-related mortality after allogenic bone marrow transplantation. Bone Marrow Transplantation 2002; 30: 441-6.

20. TAKatsuka $\mathrm{H}$, Takemoto $\mathrm{Y}$, Yamada S, Wada $\mathrm{H}$, TamuRa S, Fujimori Y et al. Complications after bone marrow transplantation are manifestations of systemic inflammatory response syndrome. Bone Marrow Transplant 2000; 26: 419-26.

21. Han Y, Doughty L, Kofos D, Sasser H, CarciLo J. Procalcitonin is persistently increased among children with poor outcome from bacterial sepsis. Pediatr Crit Care Med 2003; 4: 21-25. 